\title{
Erratum to: Renewable Energy Policies and Technological Innovation: Evidence Based on Patent Counts
}

\author{
Nick Johnstone ${ }^{1}$ • Ivan Haščič² David Popp $^{3,4}$
}

Published online: 23 August 2017

(c) Springer Science+Business Media B.V. 2017

\section{Erratum to: Environ Resource Econ (2010) 45:133-155 DOI 10.1007/s10640-009-9309-1}

While replicating the study of Johnstone et al. (2010), Bruns and Kalthaus (2017, forthcoming) noted that a dummy variable for one country (New Zealand) is missing in the reported regressions for solar patents. ${ }^{1}$ The authors have re-estimated the models including the dummy variable, and the corrected results are reported alongside the original results in the table below. The first part of the table corresponds to the results presented in Table 5 in the original paper. The second part of the table corresponds to the results presented in Table 6, where the policy dummies other than those of primary interest (feed-in tariffs and renewable energy certificates) are combined into a single variable to avoid potential multicollinearity. The third part of the table corresponds to the results presented in Table 7, where we also drop the Kyoto Protocol dummy variable.

1 The authors gratefully acknowledge Stephan Bruns and Martin Kalthaus for bringing this to our attention. The authors have verified that the results for all other technologies reported in the original paper are correct.

The online version of the original article can be found under doi:10.1007/s10640-009-9309-1.

$凶$ Nick Johnstone

Nick.Johnstone@oecd.org

Ivan Haščič

Ivan.Hascic@oecd.org

David Popp

dcpopp@maxwell.syr.edu

1 Structural Policy Division, OECD Directorate for Science, Technology and Innovation, 2 rue André Pascale, 75775 Paris Cedex 16, France

2 Environmental Performance and Information Division, OECD Environment Directorate, 2 rue André Pascale, 75775 Paris Cedex 16, France

3 The Maxwell School, Syracuse University, 426 Eggers, Syracuse, NY 13244-1020, USA

4 NBER, Cambridge, MA, USA 


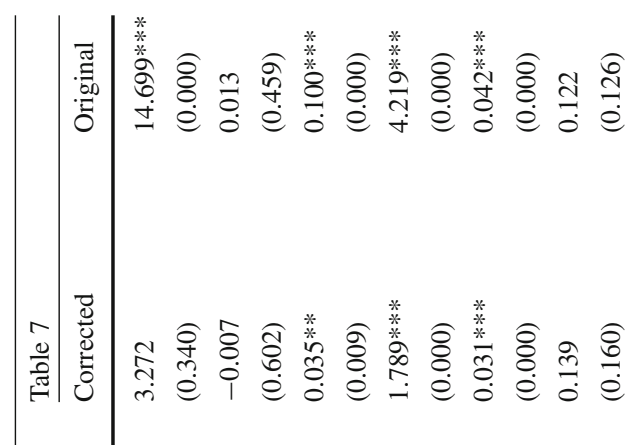

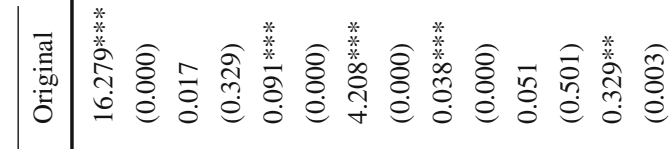

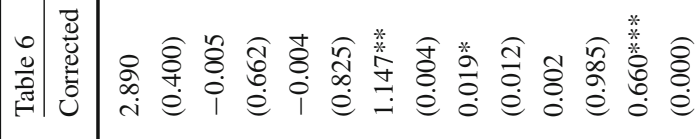

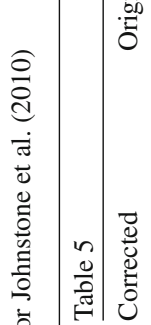

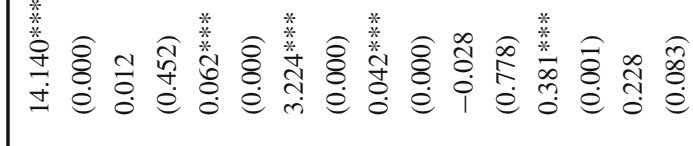

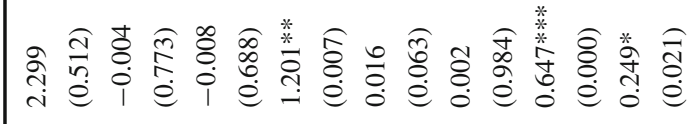

节

㕦

อ

흥

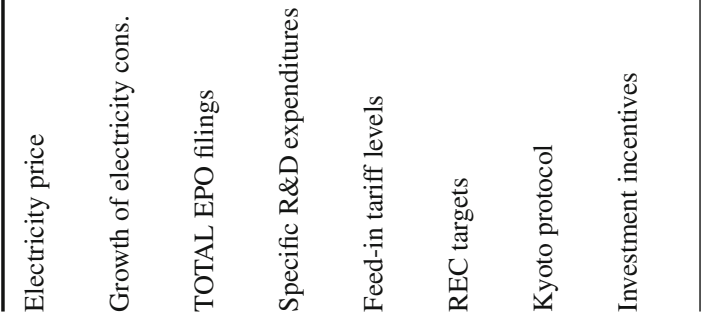




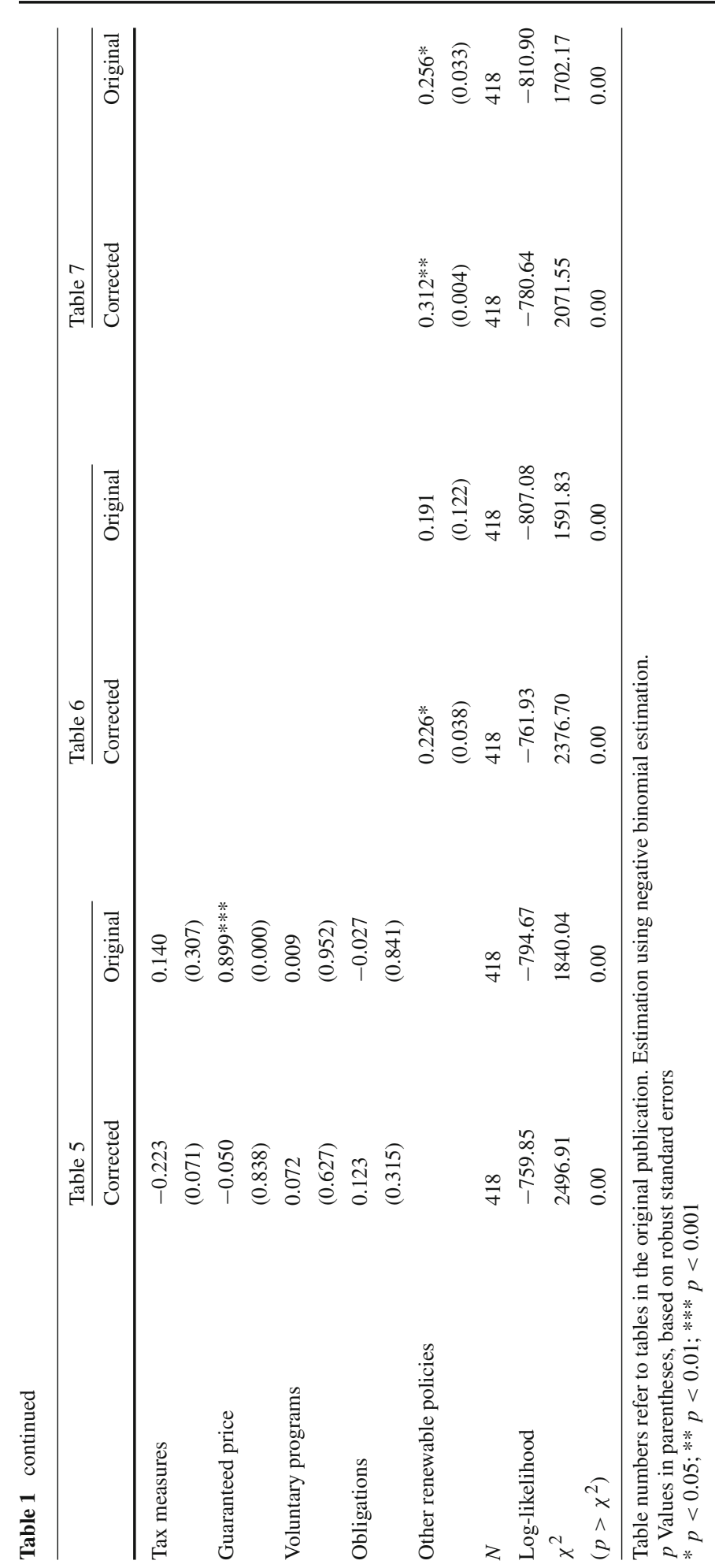


Given the focus of the paper on the role of feed-in tariffs and renewable energy certificates on patented invention of different renewable energy sources, it is important to note that the variable capturing feed-in tariff levels is now insignificant at the 5\% level for the first model estimated (the $p$ value is now 0.063). However, it remains significant when the other policy dummy variables are combined into a single variable to avoid multicollinearity (Tables 6, 7 in the original paper). The inclusion of the missing dummy variable also results in the loss of statistical significance and a much lower magnitude for the coefficient for electricity price. The change in this result is now consistent with the result for electricity prices for the other technologies reported in the paper, and is in line with results from other studies (e.g., Nesta et al. 2014).

In addition, results for two policies represented only by dummy variables change: Investment incentives now have a statistically significant impact in the first model estimated, whereas guaranteed prices do not. The results remain similar when combining all other policies into a single dummy variable for Tables 6 and 7, with a slight gain in precision. Total EPO patent filings are no longer significant in the specifications corresponding with Tables 5 and 6, which is now in line with the results presented for renewables in general. As this variable is simply a control for cross-country differences in patenting behavior, this change suggests that fully capturing all country fixed effects is sufficient to control for cross-country patenting differences.

\section{References}

Bruns SB, Kalthaus M (2017) Flexibility in the selection of patent counts: implications for $p$-hacking and policy recommendations. Mimeo. http://www.stephanbbruns.de/fileadmin/user_upload/Bruns_Kalthaus_ 2017.pdf

Nesta L, Vona F, Nicolli F (2014) Environmental policies, competition and innovation in renewable energy. J Environ Econ Manag 67:396-411 